\section{Cataract Surgery in Patients with Age-Related Macular Degeneration}

\section{Monica Asencio Duran ${ }^{1}$, Roslyn Kathryn Manrique Lipa ${ }^{2 *}$, Eugenia González Sánchez ${ }^{3}$, Jesús García Martínez ${ }^{1}$ and Bruno Casco Silva ${ }^{1}$}

'Ophthalmology Service, Hospital Universitario La Paz, Madrid, Spain

${ }^{2}$ Ophthalmology Service, Institut Català de Retina, Barcelona, Spain

${ }^{3}$ Ophthalmology Service, Hospital Santa Bárbara de Soria, Soria, Spain

\begin{abstract}
There are many common factors that share cataract and AMD. Both of them increases incidence as people age and factors as tobacco, solar exposition, heritage, free radicals and cardiovascular factors are found in cataract and AMD. Then, it is less likely to detect AMD in patients who have a moderate-severe lens opacity; and finally, cataract surgery in any way could predispose to develop AMD, perhaps through inflammatory mechanisms, or increased light transmittance with formation of free radicals; but, these assumptions have not been correlated in clinical studies, possibly because of the multifactorial conditions that share cataract and AMD. However, cataract surgery has demonstrated to be a safe procedure in the majority of cases (95\%), making possible improved vision and quality of life in these patients even in the more advanced stage.
\end{abstract}

\section{Introduction}

Age-related cataracts are a worldwide cause of blindness in 10.8 million of people and 35.1 million were visually impaired in 2010 , it means that cataract caused $33.4 \%$ of blindness and $18.5 \%$ of moderate to severe vision impairment [1]. Cataract prevalence increase as people age, by age 75 , half of population have a cataract; by age $80,70 \%$ of whites, $53 \%$ of Africans and $61 \%$ of Hispanics $[1,2]$. Cataract surgery is a successful procedure in the majority of cases (about 95\%) [2]. Although, it is not free of complications, because of the surgical procedure itself or due to coexisting ocular pathology; for example, the global incidence of post surgical cystoid macular edema is about $1.17 \%$, but it is 4 -fold increase in eyes with diabetic retinopathy, 5.6-fold in epiretinal membrane and 30-fold in retinal

*Corresponding author: Roslyn Kathryn Manrique Lipa, Ophthalmology Service, Institut Català de Retina, Barcelona, Spain, Tel: +34 671720819; E-mail: Roslyn_kml@yahoo.es

Citation: Duran MA, Lipa RKM, Sánchez EG, Martínez JG, Silva BC (2016) Cataract Surgery in Patients with Age-Related Macular Degeneration. J Ophthalmic Clin Res 3: 023.

Received: May 31, 2016; Accepted: August 11, 2016; Published: August 25, 2016 vein occlusion, nonetheless this data it is still inconclusive in age-related macular degeneration [1-3].

Age related-Macular Degeneration (AMD) is an acquired condition of the retina that causes significant central visual impairment and legal blindness in elderly people $[4,5]$. In the United States, the prevalence of AMD for people older than 40 years is estimated at $9.2 \%$, then it increases exponentially, reaching $22.8 \%$ after 75 years old [6,7]. Recently (2016) an incidence study selected by ethnicity in a population based in the United States was published, finding an overall incidence of $4.1 \%$ in Early AMD and 2.3\% in late AMD, the white population is the most affected population by $5.3 \%$ and $4.1 \%$ respectively [3].

Thus, cataract and AMD are both age-related conditions that share similar comorbidities (hereditary, cardiovascular risk, free radicals, tobacco, sun exposition, etc.) [5,8-12]. It is difficult to demonstrate a correlation between cataract surgery and AMD progression or deterioration because of this close relationship. Also, cataract development itself could preclude visualization of posterior pole and prevent a correct diagnosis of AMD [13-16]. Despite this, concern still exists in ophthalmologists about the behavior of the AMD or the choroidal neovascularization in a patient undergoing cataract surgery.

The possible relationship of AMD and cataract surgery was reviewed and discussed. A very extensive searching was made; we analyzed randomized and non-randomized control trials, prospective and clinical trials. We discuss separately each type of AMD following AREDS classification. Likewise, we have intended to extract some recommendations to follow in this complicated scenario according recently clinical evidence.

\section{Early-Intermediate AMD and Cataract Surgery}

There are at least four main studies concerning cataract surgery and AMD development, the Beaver Dam Study (BDS), Blue Mountains eye Study (BMS), Rotterdam Eye Study, Los Angeles Latino Eye Study (LALOS). They evaluated the incidence of early manifestations of AMD in patients without signs of AMD at baseline who were submitted to cataract surgery and they did not find a relationship with early AMD.

However, there are numerous publications found a possible relationship and they have suggested mechanisms that could lead to progression in AMD after phacoemulsification: First, it seems that cataract extraction with implantation of an intraocular lens increases the transmission of ultraviolet and blue light, and therefore may accelerate the development of age-related macular degeneration by producing free radicals in the retina [17-19]. Some authors could demonstrate an increase in macular pigment not influenced for the lens opacification or the patient's age [20-22]. Macular pigments, composed by carotenoids lutein, zeaxanthin and meso-Z, has a maximum absorption at $460 \mathrm{~nm}$ and protects the retina from (photo)-oxidative injury [21,23]. This assumption is theoretical or based in observation in cell culture or animal experiments and photo-toxicity as a risk factor of AMD could not have been proved in large multicenter and/or epidemiological studies. 
Second theory, the immune system and inflammatory response may induce AMD progression after cataract surgery; the pathophysiology of AMD depends on the imbalance in inflammatory regulation. A study in diabetics and cataract extraction reported an increase of VEGF (64 npm to $746 \mathrm{npm}$ ), cytokine levels in aqueous humor the day after surgery $[18,19,24]$.

Despite there is not clear a relationship between cataract surgery and AMD progression, there are studies that suggest the benefits from cataract extraction in patients with AMD in terms of visual function and quality of life, concluding that cataract surgery is cost-effective procedure in all subtypes of AMD [25-29].

Accordingly published data, cataract surgery in early AMD is beneficial in terms of vision recovery and quality of life, despite of the inconsistent data to establish or deny an association of surgery and AMD progression; probably, a previous evaluation of the risk of progression of late AMD (AREDS punctuation) must get before indicate surgery in this scenario.

\section{Advanced AMD and Cataract Surgery}

The overall incidence of late AMD is approximately $1.74 \%$ (geographic atrophy about $0.81 \%$ and neovascular AMD about $1.02 \%)$, this entity is the main cause of blindness in older population in developed countries [6].

\section{Geographic AMD}

Zhou et al., published a meta-analysis about risk of geographic atrophy and cataract surgery; the main studies analyzed were: BDS (2002), BMS (2006), AREDS (2009) and LALES (2010). A non-association between cataract surgery and geographic atrophy was found (overall OR 3.23 (95\% CI 0.63-16.47)) [30].

On the contrary, in the histopathological study from van der Schaft and Cols a higher prevalence of hard drusen and disciform scars were found in pseudophakic eyes compared to phakic eyes, although there was no statistical difference [14].

The Rotterdam Eye Study published a correlation, particularly between homozygous $\mathrm{CFH} \mathrm{Y402H} \mathrm{genotype} \mathrm{carriers} \mathrm{and} \mathrm{the} \mathrm{risk} \mathrm{of}$ dry AMD compared to heterozygous and non-carriers after cataract surgery [31].

Moreover, quantification of macular changes has been studied by infrared Autofluorescence (AF) in patients with dry AMD who were submitted to cataract extraction, and the amount of AF was increased by the surgery, but this result could not be discriminated from the change in lens status itself [32]. In addition, news tools as the MD3RI software (a computer-aided image quantification) do not found changes in Cumulated Drusen or Geographic Atrophy area Size (CDGAS) after 12 months of cataract surgery [33]. Conversely, Pipis et al., utilize modern software integrated to optical coherence tomography (advanced software of RPE) and suggest that blue light-filtering intraocular lenses have a significant photoprotective effect on the progression of geographic atrophy after cataract surgery [34].

Again, although there is not a clear association between cataract surgery and progression of geographic atrophy; visual recovery and quality of life is also increased in these patients as AREDS study reported and nowadays, cataract surgery can offer the opportunity of implanting special optics IOLs $[35,36]$, to increase magnification or displace the image to healthy retina; the initials clinical results of a telescopic IOL implanted in patients with dry macular degeneration are safely and acceptable visual quality [35].

\section{Neovascular AMD}

It is known that neovascular AMD, can compromise in $90 \%$ of cases severely the vision (20/200 or worse) if left untreated [37], but with the advent of anti-vascular Endothelial Growth Factor (anti-VEGF) intravitreal injections as therapy in wet AMD has got stabilize (90\%) or even improved vision (30\%) in a large number of cases [38-43].

The 10-year follow-up of the BMS, as well many others epidemiological studies, observed the development of neovascular AMD in $3.7 \%$ of subjects followed, and an increase in incidence in presence of cataract surgery with an odds ratio of 3.3 (95\% CI, 1,1-9.9) [44-48]. However AREDS report 25 [49] study demonstrated no clear effect of cataract surgery on the risk of progression to advanced AMD, likewise the study from Sutter and Cols [41] concluded that pseudophakia did not raise the risk of development of neovascular AMD (odds ratio of 1.035; CI 95\% 0.770-1.391).

More recently, studies published have not showed an increase in recurrence, number of injections or worsening of visual acuity when compared with non-operated eyes [15,16,25-27,39-43,50-56]. However, Lee and cols. studied the risk factors associated with recurrence of exudation in a series of 39 post-surgical patients previously treated with anti-VEGF for exudative AMD. They found that shorter delays of cataract surgery after diagnosis of wet AMD and shorter exudation-free periods before cataract surgery were associated with increased risk of recurrence. Thus, they suggested lower risk of recurrence for eyes with stabilized exudation more than 12 months; but, unfortunately this study did not compare with a control group (non-surgical group) [38].

Some other authors have suggested a significant increase in macular thickness at first month after cataract surgery that resolved at the third month, this finding could probably correspond to augmented susceptibility to surgical cystoid macular edema, and not related to recurrence of $\mathrm{CNV}$; however these findings were not properly evaluated with a Fluorescein Angiogram (FAG) [39,52].

Baek et al., proposed the increased frequency of Posterior Vitreous Detachment (PVD) after cataract surgery as a risk factor that could affect the pharmacokinetics or therapeutic effect of anti-VEGF. The study concluded that anti-VEGF agents could penetrate more effectively in operated eyes, but at the same time this may offset by increased clearance promoted in PVD state [40].

A possible relationship between repeated intravitreal injections and increased risk of posterior capsular rupture (2.59 times higher) have been recently published, although this relationship needs to be confirmed with more randomized clinical studies [57].

The studies published about cataract surgery in patients with neovascular AMD are mainly retrospective, FAG was only performed as a diagnostic test and not on the follow-up; some of them without control group and with short periods of follow-up [15,16,25-27,39$43,50-55,58]$. In addition, the protocols used in the reported studies, were inhomogeneous (treat and extend, pro-re-nata and monthly injections), but none compared these protocols between them, or even between different anti-VEGF agents (bevacizumab, ranibizumab or aflibercept) [38,39,41-43,52-55]. Then, it is required prospective research of causality and not only epidemiological studies, with long periods of follow-up to clarify studies published until now concerning this issue. 
Citation: Duran MA, Lipa RKM, Sánchez EG, Martínez JG, Silva BC (2016) Cataract Surgery in Patients with Age-Related Macular Degeneration. J Ophthalmic Clin Res 3: 023.

\section{Conclusion}

Some pearls can be extracted from these studies: patients with early AMD benefit most from cataract surgery. Also, cataract surgery could be offered to patients with geographic atrophy, in cases with moderate-advanced cataract to improve the visualization of the posterior pole, to improve peripheral vision or in patients with extra-foveal atrophy. In neovascular AMD cases should be stressed the importance of a period time of disease stabilization (6-12 months); the possibility of anti-VEGF intravitreal injection use in peri-operative period (1-2 weeks before cataract surgery, or combined during cataract surgery); a closely monitoring (monthly) in post-surgical patients, especially in those with less than 12 months of stabilization; and, last, if recurrence is suspected, a fluorescein angiogram is recommended in order to establish recurrence related to AMD or to cataract surgery.

qStill, there is insufficient information to support the implantation of light-filtering intraocular lenses for the prevention of the development or progression of AMD, as photo-toxicity could not demonstrate a clear relation with AMD in population studies, so it necessary more clinical studies with sufficient evidence to extrapolate recommendations about this issue.

\section{References}

1. Khairallah M, Kahloun R, Bourne R, Limburg H, Flaxman SR, et al. (2015) Number of people blind or visually impaired by cataract worldwide and in world regions, 1990 to 2010. Invest Ophthalmol Vis Sci 56: 6762-6769.

2. World Health Organization. What are the vision 2020 objectives for cataract intervention? World Health Organization, Geneva, Switzerland.

3. Fisher DE, Klein BE, Wong TY, Rotter JI, Li X, et al. (2016) Incidence of Age-related Macular Degeneration in a Multi-ethnic United States population: The Multi-Ethnic Study of Atherosclerosis. Ophthalmology 123: 1297-1308.

4. Coleman HR, Chan CC, Ferris FL, Chew EY (2008) Age-related macular degeneration. Lancet 372: 1835-1845.

5. Krishnaiah S, Das T, Nirmalan PK, Nutheti R, Shamanna BR, et al. (2005) Risk factors for age-related macular degeneration: findings from the Andhra Pradesh eye disease study in South India. Invest Ophthalmol Vis Sci 46: 4442-4449.

6. Algvere PV, Marshall J, Seregard S (2006) Age-related maculopathy and the impact of blue light hazard. Acta Ophthalmol Scand 84: 4-15.

7. Bird AC, Bressler NM, Bressler SB, Chisholm IH, Coscas G, et al. (1995) An international classification and grading system for age-related maculopathy and age-related macular degeneration. The International ARM Epidemiological Study Group. Surv Ophthalmol 39: 367-374.

8. Age-Related Eye Disease Study Research Group (2001) A randomized, placebo-controlled, clinical trial of high-dose supplementation with vitamins C and $E$, beta carotene, and zinc for age-related macular degeneration and vision loss: AREDS report no. 8. Arch Ophthalmol 119: 1417-1436.

9. Evans JR (2006) Antioxidant vitamin and mineral supplements for slowing the progression of age-related macular degeneration. Cochrane Database of Systemic Reviews

10. VEGF Inhibition Study in Ocular Neovascularization (V.I.S.I.O.N.) Clinical Trial Group, D'Amico DJ, Masonson HN, Patel M, Adamis AP, et al. (2006) Pegaptanib sodium for neovascular age-related macular degeneration: twoyear safety results of the two prospective, multicenter, controlled clinical trials. Ophthalmology 113: 992-1001.

11. Rosenfeld PJ, Brown DM, Heier JS, Boyer DS, Kaiser PK, et al. (2006) Ranibizumab for neovascular age-related macular degeneration. $N$ Engl J Med 355: 1419-1431.

12. Klein R, Klein BE, Wang Q, Moss SE (1994) Is age-related maculopathy associated with cataracts? Arch Ophthalmol 112: 191-196.
13. van der Schaft TL, Mooy CM, de Bruijn WC, Mulder PG, Pameyer JH, et al. (1994) Increased prevalence of disciform macular degeneration after cataract extraction with implantation of an intraocular lens. $\mathrm{Br} \mathrm{J}$ Ophthalmol 78: 441-445.

14. Klein R, Klein BE, Linton KL (1992) Prevalence of age-related maculopathy. The Beaver Dam Eye Study. Ophthalmology 99: 933-943.

15. Freeman EE, Munoz B, West SK, Tielsch JM, Schein OD (2003) Is there an association between cataract surgery and age-related macular degeneration? Data from three population-based studies. Am J Ophthalmol 135: 849-856.

16. Age-Related Eye Disease Study 2 Research Group, Huynh N, Nicholson BP, Agrón E, Clemons TE, et al. (2014) Visual acuity after cataract surgery in patients with age-related macular degeneration: age-related eye disease study 2 report number 5. Ophthalmology 121: 1229-1236.

17. Klein R, Klein BE, Wong TY, Tomany SC, Cruickshanks KJ (2002) The association of cataract and cataract surgery with the long-term incidence of age-related maculopathy: the Beaver Dam eye study. Arch Ophthalmol 120: $1551-1558$.

18. Bockelbrink A, Roll S, Ruether K, Rasch A, Greiner W, et al. (2008) Cataract surgery and the development or progression of age-related macular degeneration: a systematic review. Surv Ophthalmol 53: 359-367.

19. Klein R, Klein BE, Jensen SC, Cruickshanks KJ (1998) The relationship of ocular factors to the incidence and progression of age-related maculopathy. Arch Ophthalmol 116: 506-513.

20. Nolan JM, O'Reilly P, Loughman J, Stack J, Loane E, et al. (2009) Augmentation of macular pigment following implantation of blue light-filtering intraocular lenses at the time of cataract surgery. Invest Ophthalmol Vis Sci 50: 4777-4785.

21. Demirel S, Bilici S, Batıoglu F, Ozmert E (2014) The effect of age and cataract surgery on macular pigment optic density: a cross-sectional, comparative study. Graefes Arch Clin Exp Ophthalmol 252: 213-218.

22. Cuthbertson FM, Peirson SN, Wulff K, Foster RG, Downes SM (2009) Blue light-filtering intraocular lenses: review of potential benefits and side effects. J Cataract Refract Surg 35: 1281-1297.

23. Shuttleworth GN, Luhishi E, Harrad R (1998) Do patients with age related maculopathy and cataract benefit from cataract surgery? $\mathrm{Br} \mathrm{J}$ Ophthalmol 82: 611-616.

24. Casparis H, Lindsley K, Kuo IC, Sikder S, Bressler NM (2013) Surgery for cataracts in people with age-related macular degeneration. Cochrane Database Systemic Review 6.

25. Dillon J, Zheng L, Merriam JC, Gaillard ER (2004) Transmission of light to the aging human retina: possible implications for age related macular degeneration. Exp Eye Res 79: 753-759.

26. Armbrecht A, Findlay C, Kaushal S, Aspinall P, Hill A, et al. (2000) Is cataract surgery justified in patients with age related macular degeneration? A visual function and quality of life assessment. $\mathrm{Br} \mathrm{J}$ Ophthalmol 84: 1343-1348.

27. Ma Y, Huang J, Zhu B, Sun Q, Miao Y, et al. (2015) Cataract surgery in patients with bilateral advanced age-related macular degeneration: Measurement of visual acuity and quality of life. J Cataract Refract Surg 41: 12481255.

28. Stock MV, Vollman DE, Baze EF, Chomsky AS, Daly MK, et al. (2015) Functional visual improvement after cataract surgery in eyes with age-related macular degeneration: Results of the ophthalmic surgical outcomes data project. Invest Ophthalmol Vis Sci 56: 2536-2540.

29. McCarty CA, Mukesh BN, Fu CL, Mitchell P, Wang JJ, et al. (2001) Risk factors for age-related maculopathy: the visual impairment project. Arch Ophthalmol 119: 1455-1462.

30. Zhou P, Ye HF, Jiang Y, Yang J, Zhu X, et al. (2012) aA crystallin may protect against geographic atrophy-meta-analysis of cataract vs. cataract surgery for geographic atrophy and experimental studies. PLoSOne 7: 43173. 
Citation: Duran MA, Lipa RKM, Sánchez EG, Martínez JG, Silva BC (2016) Cataract Surgery in Patients with Age-Related Macular Degeneration. J Ophthalmic Clin Res 3: 023.

31. Schachar IH, Zahid S, Comer GM, Stem M, Schachar AG, et al. (2013) Quantification of fundus autofluorescence to detect disease severity in nonexudative age-related macular degeneration. JAMA Ophthalmol 131: 1009-1015.

32. Ciulla TA, Hammond BR Jr, Yung CW, Pratt LM (2001) Macular pigment optical density before and after cataract extraction. Invest Ophthalmol Vis Sci 42: 1338-1341.

33. Brunner S, Mora A, Fonseca J, Weber T Falkner-Radler Cl, et al. (2013) Monitoring of drusen and geographic atrophy area size after surgery using the MD3RI tool for computer-aided contour drawing Opthalmologica 229: 86-93.

34. Pipis A, Touliou E, Pillunat LE, Augustin AJ (2015) Effect of the blue filter intraocular lens on the progression of geographic atrophy. Eur $\mathrm{J}$ Ophthalmo 25: 128-133.

35. Hengerer FH, Artal P, Kohnen T, Conrad-Hengerer I (2015) Initial clinical results of a new telescopic IOL implanted in patients with dry age-related macular degeneration. J Refract Surg 31: 158-162.

36. Potgieter FJ, Claoué CM (2014) Safety and efficacy of an intraocular Fresne prism intraocular lens in patients with advanced macular disease: initial clinical experience. J Cataract Refract Surg 40: 1085-1091.

37. Lee TG, Kim JH, Chang YS, Kim CG, Kim JW (2014) Factors influencing the exudation recurrence after cataract surgery in patients previously treated with anti-vascular endothelial growth factor for exudative age-related macular degeneration. Graefes Arch Clin Exp Ophthalmol 252: 1573-1579.

38. Saraf SS, Ryu CL, Ober MD (2015) The effects of cataract surgery on patients with wet macular degeneration. Am J Ophthalmol 160: 487-492.

39. Tabandeh H, Chaudhry NA, Boyer DS, Kon-Jara VA, Flynn HW Jr (2012) Outcomes of cataract surgery in patients with neovascular age-related macular degeneration in the era of anti-vascular endothelial growth factor therapy. J Cataract Refract Surg 38: 677-682.

40. Wang JJ, Rochtchina E, Lee AJ, Chia EM, Smith W, et al. (2007) Ten-year incidence and progression of age-related maculopathy: the blue Mountains Eye Study. Ophthalmology 114: 92-98.

41. Rosenfeld PJ, Shapiro H, Ehrlich JS, Wong $P$, MARINA and ANCHOR Study Groups (2011) Cataract surgery in ranibizumab-treated patients with neovascular age-related macular degeneration from the phase 3 ANCHOR and MARINA trials. Am J Ophthalmol 152: 793-798.

42. Ozkaya A, Alkin Z, Yilmaz I, Yazici AT (2015) Comparison of intravitreal ranibizumab between phakic and pseudophakic neovascular age-related macular degeneration patients: Two-year results. Saudi J Ophthalmol 29: 182-186.

43. Grixti A, Papavasileiou E, Cortis D, Kumar BV, Prasad S (2014) Phacoemulsification surgery in eyes with neovascular age-related macular degeneration. ISRN Ophthalmol.

44. Cugati S, Mitchell P, Rochtchina E, Tan AG, Smith W, et al. (2006) Cataract surgery and the 10-year incidence of age-related maculopathy: the Blue Mountains Eye Study. Ophthalmology 113: 2020-2025
45. Wang JJ, Klein R, Smith W, Klein BE, Tomany S, et al. (2003) Cataract surgery and the 5-year incidence of late-stage age-related maculopathy: pooled findings from the Beaver Dam and Blue Mountains eye studies. Ophthalmology 110: 1960-1967.

46. Buch H, Vinding T, La Cour M, Jensen GB, Prause JU, et al. (2005) Risk factors for age-related maculopathy in a 14-year follow-up study: the Copenhagen City Eye Study. Acta Ophthalmol Scand 83: 409-418.

47. Ho L, Boekhoorn SS, Liana, van Duijn CM, Uitterlinden AG, et al. (2008) Cataract surgery and the risk of aging macula disorder: the rotterdam study. Invest Ophthalmol Vis Sci 49: 4795-4800.

48. Sutter FK, Menghini M, Barthelmes D, Fleischhauer JC, Kurz-Levin MM, et al. (2007) Is pseudophakia a risk factor for neovascular age-related macular degeneration? Invest Ophthalmol Vis Sci 48: 1472-1475.

49. Chew EY, Sperduto RD, Milton RC, Clemons TE, Gensler GR, et al. (2009) Risk of advanced age-related macular degeneration after cataract surgery in the Age-Related Eye Disease Study: AREDS report 25. Ophthalmology 116: 297-303.

50. Ohr M, Kaiser PK (2012) Intravitreal aflibercept injection for neovascular (wet) age-related macular degeneration. Expert Opin Pharmacother 13: 585-591.

51. Wang JJ, Mitchell PG, Cumming RG, Lim R (1999) Cataract and age-related maculopathy: the Blue Mountains Eye Study. Ophthalmic Epidemiol 6: 317326.

52. Baek JS, Cho HJ, Cho SW, Kim CG, Kim JW (2013) Intravitreal ranibizumab injection for neovascular age-related macular degeneration in phakic versus pseudophakic eyes. Retina 33: 467-473.

53. Baatz H, Darawsha R, Ackermann H, Scharioth GB, de Ortueta D, et al (2008) Phacoemulsification does not induce neovascular age-related macular degeneration. Invest Ophthalmol Vis Sci 49: 1079-1083.

54. Weinberg DV, Shapiro H, Ehrlich JS (2013) Ranibizumab treatment outcomes in phakic versus pseudophakic eyes: an individual patient data analysis of 2 phase 3 trials. Ophthalmology 120: 1278-1282.

55. Forooghian F, Agrón E, Clemons TE, Ferris FL 3rd, Chew EY, et al. (2009) Visual Acuity Outcomes after cataract surgery in patients with age-related macular degeneration: Age-related Eye disease study report no. 27. Ophthalmology 116: 2093-2100.

56. Kessel L, Erngaard D, Flesner P, Andresen J, Tendal B, et al. (2015) Cataract surgery and age-related macular degeneration. An evidence-based update. Acta Ophthalmol 93: 593-600.

57. Lee AY, Day AC, Egan C, Bailey C, Johnston RL, et al. (2016) Previous intravitreal therapy is associated with increased risk of posterior capsule rupture during cataract surgery. Ophthalmology 123: 1252-1256.

58. Kessel L, Theil KP, Sørensen LT, Munch IC (2016) Cataract surgery in patients with neovascular age-related macular degeneration. Acta Ophthalmol. 